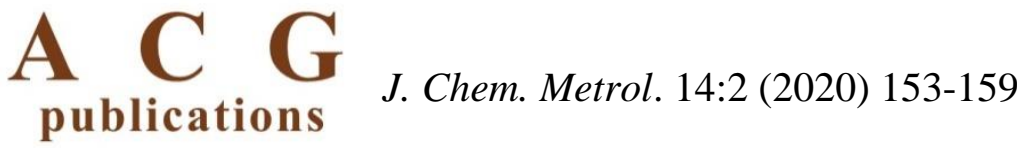
journal of chemical
metrology

\title{
Determination of simethicone in different drug formulations by gravimetry and comparison with the FTIR method
}

\author{
Müge Güleli ${ }^{1}$, Sezin İşsever ${ }^{1}$, Cem Çalışkan ${ }^{2 *}$ and \\ Mahmut Özbek@1 \\ World Medicine Pharmaceutical Industry and Trade Inc. R\&D Center, 15 Temmuz Mah. Cami yolu \\ Cad. No:50 K:4 Günesli/İstanbul, Türkiye \\ Department of Chemistry, Yildiz Technical University, Davutpasa Campus, 34220, Esenler, Istanbul, T \\ Türkiye
}

(Received July 01, 2020; Revised July 29, 2020; Accepted August 16, 2020)

\begin{abstract}
Fourier transform infrared (FTIR) spectroscopy was mostly used in both pharmacopeia and literature studies to determine the assay of simethicone (SMT) in pharmaceuticals. It should be noted that HPLC is used less frequently. As an alternative to the mentioned methods a new, simple, fast, easy-to-apply and very cheap gravimetric method was developed and validated according to ICH guidance entitled Q2B Validation of Analytical Procedures: Methodology for the quantification analysis of simethicone in different pharmaceutical forms. For the simethicone suspension product provided to alleviate too much gas in the gastrointestinal tract, the simethicone amount was determined both by the validated gravimetric method and by the FTIR method defined in the USP and BP monographs, and the results were within the acceptance criteria. It is emphasized that there is no significant difference between the results of gravimetric and FTIR methods according to the calculated F- and t-test results.
\end{abstract}

Keywords: Simethicone; gravimetry; F- and t-test; method validation; assay. @ 2020 ACG Publications. All rights reserved.

\section{Introduction}

Simethicone, a silicon-based organic polymer, is widely found in drug formulations used in the treatment of conditions caused by excessive gas due to its anti-foaming properties. It is used as an active ingredient or excipient in different drug forms such as capsule, drop, suspension, chewable tablet and is preferred in the treatment of diseases such as heartburn, gastric ulcer, colic, sensitive bowel syndrome [14].

In literature studies, there are HPLC methods with UV or evaporative light scattering detectors (ELSD) for the determination of simethicone [4-8], but these methods are not found in raw material and finished product monographs. The absence of chromophore groups in the simethicone structure makes it difficult to work with the UV detector. The methods in the literature were tried, but the areas were not taken as stated. Because it does not have a solubility in solvents such as water, alcohol and does not contain chromophore groups, it makes HPLC-UV detector studies difficult. Due to these features, evaporative light scattering detectors have been put into use for high-performance liquid chromatography for simethicone, which has working difficulties. An evaporative light scattering detector is commonly used for the analysis of compounds where UV detection might be a restriction, and it can detect all compounds which are non-volatile and semi-volatile. However, since special detectors such as ELSD are

* Corresponding author E-Mail: caliskan@ worldmedicine.com.tr

The article was published by ACG Publications

http://www.acgpubs.org/journal/journal-of-chemical-metrology July-December 2020 EISSN:1307-6183

DOI:http://doi.org/10.25135/jcm.44.20.07.1701 
not easily found in every sector and laboratory, it is necessary to add new methods to the literature for the determination of molecules such as simethicone.

In pharmacopeia research, there are analytical methods reported for many product forms such as tablets, capsules, oral suspension, chewable tablets which are containing simethicone in British (BP), and US Pharmacopeias (USP) [9, 10]. Almost all of the methods in these pharmacopeias are carried out by Fourier-transform infrared (FTIR) spectroscopy for the quantification or recognition of simethicone. Besides, the majority of literature researches includes the FTIR method [1, 11-14]. Although this method is suitable for the raw material, the stability and robustness of the FTIR method are not as suitable as other analytical methods, given the effects of the placebo components for the finished product forms. Considering all these, a new gravimetric method was tried and validated to be an alternative to FTIR and HPLC methods. This method, which can be easily applied without the need for any derivatization and costly devices, is quite simple and economical.

The product we use in our study is an oral suspension produced by our company that contains aluminum hydroxide, magnesium hydroxide, and simethicone as active ingredients. Quantification of simethicone for this product had been studied and validated both by gravimetric method and FTIR spectroscopy specified in the finished product monographs. The results obtained by both methods compared statistically.

\section{Experimental}

\subsection{Materials and Methods}

A high purity grade sample of SMT was purchased from USP and was supplied as raw material from Riocare India Pvt. Ltd. The suspension product had been improved by the World Medicine Pharmaceutical Industry and Trade Inc. (Istanbul, Turkey). Sodium hydroxide pellets, toluene, diethyl ether, hydrochloric acid and sodium sulphate anhydrous were bought from Merck. The Sartorius Stedim Biotech system was used to produce liquid chromatography grade water.

A Shimadzu IRAffinity-1 FTIR spectrophotometer was used in the $400-4000 \mathrm{~cm}^{-1}$ scan range. Each spectrum was automatically averaged over 20 scans obtained at a spectral resolution of $5 \mathrm{~cm}^{-1}$. Data processing and evaluations were made by benefit from IR solution software.

\subsection{Preparation of Solutions for FTIR Method}

The oral suspension equivalent to $50 \mathrm{mg}$ of simethicone is weighed into a $120 \mathrm{~mL}$ round bottom flask. $40 \mathrm{~mL}$ of $0.1 \mathrm{~N}$ sodium hydroxide is added and the solution is mixed until dispersion. $25.0 \mathrm{~mL}$ of toluene is added on it and the cap is tightly closed. Agitate in the mixer for 15 minutes with 200 oscillations / minute and a $38 \pm 2 \mathrm{~mm}$ stroke. The mixture is transferred to a $125 \mathrm{~mL}$ separatory funnel. Approximately $5 \mathrm{~mL}$ of upper organic layer is removed to a $15 \mathrm{~mL}$ test tube containing $0.5 \mathrm{~g}$ of anhydrous sodium sulfate. Cap the tube with a stopper having an inert liner, shake vigorously, and centrifuge the mixture until a clear supernatant is obtained.

In parallel, prepare the standard solution similarly. $50 \mathrm{mg}$ USP Polydimethylsiloxane RS is dissolved in $25.0 \mathrm{~mL}$ toluene. Add $40 \mathrm{~mL}$ of $0.1 \mathrm{~N}$ sodium hydroxide and equal volume of water to the oral suspension sample taken for the sample solution.

Determine solution absorption in 0.5 -mm cells at absorption maximum wavelength of about 7.9 $\mu \mathrm{m}$ with the help of an appropriate infrared spectrometer, using a reference solution for apparatus calibration.

\subsection{Preparation of Solutions for Gravimetric Method}

Shake well the vial with suspension and accurately weighed amount of homogeneous suspension, equivalent to $20 \mathrm{~mL}$ of suspension, is quantitatively transferred to a separation funnel. Add $15 \mathrm{~mL}$ of concentrated hydrochloric acid and mix carefully. Extract with ether $(5 \times 50 \mathrm{~mL}$ portions), filter through sodium sulfate anhydrous into a preliminary weighed round bottom flask. Evaporate filtered extract and dry the residue at $80^{\circ} \mathrm{C}$ for 2 hours. 
Likewise, prepare the standard solution. Weigh accurately Simethicone equivalent to $500.0 \mathrm{mg}$ SMT, is quantitatively transferred to a separation funnel. Add $15 \mathrm{~mL}$ of concentrated hydrochloric acid and mix carefully. Extract with ether $(5 \times 50 \mathrm{~mL}$ portions), filter through sodium sulfate anhydrous into a preliminary weighed round bottom flask. Evaporate filtered extract and dry the residue at $80^{\circ} \mathrm{C}$ for 2 hours. Determine the weight of the obtained dried residue.

Amount of simethicone was estimated using following equation,

$$
\mathrm{g} / 100 \mathrm{~mL}=\frac{m \times \rho \times 100}{a}
$$

where:

$m$ : Weight of dried residue, $\mathrm{g}$;

$\rho$ : Density of suspension, $\mathrm{g} / \mathrm{mL}$;

$a$ : Weighed amount of suspension, $\mathrm{g}$;

\section{Results and Discussion}

For our suspension product, SMT quantification analysis was performed with both the FTIR method and the gravimetric method. Validation parameters were studied for these methods following the ICH guidelines and literature $[15,16]$. Common parameters were evaluated statistically. For this, t-test and F-test were applied to the results obtained.

The FTIR spectrum of the peak, which is obtained by separating from noise and other components and which is the identifier for simethicone at $1263 \mathrm{~cm}^{-1}$, is shown in Figure 1. By making use of the absorbance value of the SMT at this point, the relevant calculations were made. In gravimetry, a calculation based on the difference of weighing taken before and after extraction was made and validation parameters were examined.

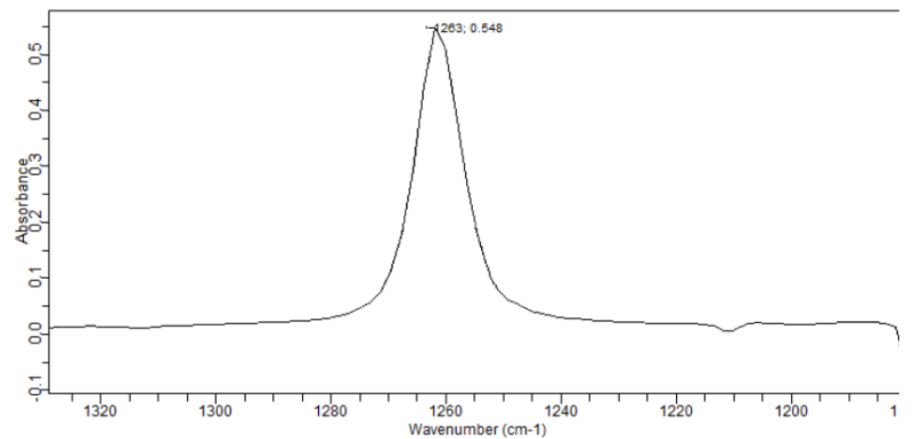

Figure 1. Infrared spectrum of Simethicone

\subsection{Linearity}

Linearity was studied in both methods. For the gravimetric method; A linearity graph was drawn between the average amount of simethicone weighed for analysis and the amount obtained at the end of the analysis. The method showed good linearity with a correlation coefficient of 0.999 (Figure S1, in supporting information).

The linearity of the FTIR method was confirmed between $0.42-3.17 \mathrm{mg} / \mathrm{mL}$ concentrations. The slope at $1263 \mathrm{~cm}^{-1}$ was 0.2636 with the intercept value of -0.0050 (Figure S2, in supporting information).

\subsection{Accuracy}

Accuracy was assessed by preparing recovery solutions for both methods in the concentration range of 50\%, 100 and $150 \%$. These were analyzed against placebo and blank solutions to ensure that there was no interference. Each recovery solution was prepared three times. The percent recovery results 
were between $98.0 \%$ and $102.0 \%$. The $\%$ RSD was less than $2.0 \%$. These results, shown in Table 1 , were within acceptable limits.

Table 1. Accuracy results of the methods

\begin{tabular}{ccc}
\hline \% Recovery & FTIR Method & Gravimetric Method \\
\hline $50 \%$ & 101.23 & 100.11 \\
$100 \%$ & 99.71 & 101.21 \\
$150 \%$ & 99.86 & 99.54 \\
Mean & $100.16 \pm 1.11$ & $100.29 \pm 0.97$ \\
RSD & 1.45 & 1.26 \\
\hline
\end{tabular}

\subsection{Precision and Intermediate Precision}

To confirm the precision of the methods, 6 different sample solutions were prepared by the same analyst on the same day and studied by two methods. The Simethicone content was determined by the FTIR method with a mean result of $2.50 \pm 0.04 \mathrm{~g} / 100 \mathrm{~mL}$ (RSD $1.35 \%$ ), by the gravimetric method with a mean result of $2.53 \pm 0.03 \mathrm{~g} / 100 \mathrm{~mL}$ (RSD $1.30 \%$ ), in good agreement with the label claim of $2.5 \mathrm{~g} / 100$ $\mathrm{mL}$.

Table 2. Precision and intermediate precision of the methods $(\mathrm{g} / 100 \mathrm{~mL})$

\begin{tabular}{c|cc|cc}
\hline & \multicolumn{2}{|c|}{ Method Precision } & \multicolumn{2}{c}{ Intermediate Precision } \\
\hline & FTIR & Gravimetric & FTIR & Gravimetric \\
& Method & Method & Method & Method \\
\hline Mean & $2.50 \pm 0.04$ & $2.53 \pm 0.03$ & $2.51 \pm 0.04$ & $2.51 \pm 0.02$ \\
SD & 0.03 & 0.03 & 0.04 & 0.02 \\
RSD & 1.35 & 1.30 & 1.61 & 0.94 \\
\hline
\end{tabular}

Similarly, the intermediate-precision results performed by different analysts on different days are similar and their values are given in Table 2. Besides, the precision RSD results also meet the acceptance criteria of the ICH guidelines.

\subsection{F- and t-Test Results}

Chemometric methods were used to examine the relationship between recovery, precision and intermediate precision results obtained by two methods, one spectrophotometric and the other gravimetric. First of all, the ANOVA F-test was applied to the results obtained in each parameter. The F-test variance analysis was applied between the gravimetric results corresponding to the FTIR results and it was observed that the $\mathrm{F}$ values obtained at the $\alpha=0.05$ significance level were greater than 1 and thus there was an $\mathrm{F}$ distribution between the results obtained. According to the relationship between $\mathrm{F}$ and $\mathrm{F}$ critical, $\mathrm{t}$-test was applied. The F-test results obtained for the recovery parameter, as seen in Table $3, \mathrm{~F} \geq 1$ and $\mathrm{F}$ $<\mathrm{F}$ critical two-tail were found. In this case, the " $\mathrm{t}$-Test: two samples assuming equal variances" test was performed and again according to the results in Table 3 it was found that $\mid \mathrm{t}$ Stat $\mid \leq \mathrm{t}$ is Critical two-tailed, it was emphasized that there is no difference between the results obtained by the two methods and therefore the recovery of the methods is equivalent.

Similar calculations were made for the precision and intermediate precision parameters, and as is the case with accuracy, it was observed that there was no difference between the results obtained by the two methods. F and t-test results obtained for these parameters are shown in Table 4 and Table 5. 
Table 3. F- and t- test results of accuracy

\begin{tabular}{|c|c|c|c|c|c|}
\hline \multicolumn{3}{|c|}{ F-test: Two sample for variances } & \multicolumn{3}{|c|}{ t-Test: Two samples assuming equal variances } \\
\hline & $\begin{array}{l}\text { FTIR } \\
\text { results }\end{array}$ & $\begin{array}{c}\text { Gravimetric } \\
\text { results }\end{array}$ & & $\begin{array}{l}\text { FTIR } \\
\text { results }\end{array}$ & $\begin{array}{c}\text { Gravimetric } \\
\text { results }\end{array}$ \\
\hline Mean $(\mathrm{g} / 0.1 \mathrm{~L})$ & 100.16 & 100.29 & Mean $(\mathrm{g} / 0.1 \mathrm{~L})$ & 100.16 & 100.29 \\
\hline Variance & 2.10 & 1.60 & Variance & 2.10 & 1.60 \\
\hline Observation & 9 & 9 & Observation & 9 & 9 \\
\hline $\mathrm{df}$ & 8 & 8 & Cumulative Variance & 1.85 & \\
\hline $\mathrm{F}$ & 1.31 & & Predicted Mean Difference & 0 & \\
\hline $\begin{array}{l}\mathrm{P}(\mathrm{F}<=\mathrm{f}) \text { one- } \\
\text { tailed }\end{array}$ & 0.36 & & df & 16 & \\
\hline $\begin{array}{l}\mathrm{F} \text { Critical two- } \\
\text { tailed }\end{array}$ & 3.44 & & t Stat & -0.20 & \\
\hline & & & $\mathrm{P}(\mathrm{T}<=\mathrm{t})$ one-tailed & 0.42 & \\
\hline & & & t Critical one-tailed & 1.34 & \\
\hline & & & $\mathrm{P}(\mathrm{T}<=\mathrm{t})$ two-tailed & 0.84 & \\
\hline & & & t Critical two-tailed & 1.75 & \\
\hline
\end{tabular}

Table 4. F- and t- test results of precision

\begin{tabular}{lcc}
\hline \multicolumn{3}{l}{ F-test: Two sample for variances } \\
\hline & $\begin{array}{c}\text { FTIR } \\
\text { results }\end{array}$ & $\begin{array}{c}\text { Gravimetric } \\
\text { results }\end{array}$ \\
\hline Mean $(\mathrm{g} / 0.1 \mathrm{~L})$ & 100.08 & 101.03 \\
Variance & 1.82 & 1.73 \\
Observation & 6 & 6 \\
$\mathrm{df}$ & 5 & 5 \\
$\mathrm{~F}$ & 1.05 & \\
$\mathrm{P}(\mathrm{F}<=\mathrm{f}) \quad$ one- & & \\
tailed & 0.48 & \\
F Critical two- & & \\
tailed & 5.05 & \\
\hline
\end{tabular}

t-Test: Two samples assuming equal variances

\begin{tabular}{lcc}
\hline & $\begin{array}{c}\text { FTIR } \\
\text { results }\end{array}$ & $\begin{array}{c}\text { Gravimetric } \\
\text { results }\end{array}$ \\
\hline Mean $(\mathrm{g} / 0.1 \mathrm{~L})$ & 100.08 & 101.03 \\
Variance & 1.82 & 1.73 \\
Observation & 6 & 6 \\
Cumulative Variance & 1.77 & \\
Predicted Mean Difference & 0 & \\
df & & \\
& 10 & \\
t Stat & & \\
P(T<=t) one-tailed & -1.23 & \\
t Critical one-tailed & 0.12 & \\
P(T<=t) two-tailed & 1.37 & \\
t Critical two-tailed & 0.25 & \\
\end{tabular}

Table 5. F- and t- test results of intermediate precision

\begin{tabular}{|c|c|c|c|c|c|}
\hline \multicolumn{3}{|c|}{ F-test: Two sample for variances } & \multicolumn{3}{|c|}{ t-Test: Two samples assuming equal variances } \\
\hline & $\begin{array}{l}\text { FTIR } \\
\text { results }\end{array}$ & $\begin{array}{c}\text { Gravimetric } \\
\text { results }\end{array}$ & & $\begin{array}{l}\text { FTIR } \\
\text { results }\end{array}$ & $\begin{array}{c}\text { Gravimetric } \\
\text { results }\end{array}$ \\
\hline Mean $(\mathrm{g} / 0.1 \mathrm{~L})$ & 100.42 & 100.33 & Mean (g/0.1 L) & 100.42 & 100.33 \\
\hline Variance & 2.62 & 0.90 & Variance & 2.62 & 0.90 \\
\hline Observation & 6 & 6 & Observation & 6 & 6 \\
\hline $\mathrm{df}$ & 5 & 5 & Cumulative Variance & 1.76 & \\
\hline $\mathrm{F}$ & 2.92 & & Predicted Mean Difference & 0 & \\
\hline $\begin{array}{l}\mathrm{P}(\mathrm{F}<=\mathrm{f}) \\
\text { tailed }\end{array}$ & 0.13 & & df & 10 & \\
\hline $\begin{array}{l}\text { F Critical two- } \\
\text { tailed }\end{array}$ & 5.05 & & t Stat & 0.12 & \\
\hline & & & $\mathrm{P}(\mathrm{T}<=\mathrm{t})$ one-tailed & 0.45 & \\
\hline & & & t Critical one-tailed & 1.37 & \\
\hline & & & $\mathrm{P}(\mathrm{T}<=\mathrm{t})$ two-tailed & 0.90 & \\
\hline & & & t Critical two-tailed & 1.81 & \\
\hline
\end{tabular}




\section{Conclusions}

A new gravimetric method was optimized for the quantitative determination of simethicone in the oral suspension product which has simethicone, aluminum hydroxide and magnesium hydroxide as active pharmaceutical ingredients in the formulation. Quite simply, economical, time-saving this new method has been validated according to regulatory guidelines and compared with the FTIR procedure recommended by the US Pharmacopeia. The statistical F-test and t-test were applied to check the results obtained by the two analytical methods. No significant differences were observed. In the results obtained, it was seen that there were no significant differences between the methods at $90 \%$ confidence level, since $\mid \mathrm{t}$ Stat $\mid \leq \mathrm{t}$ was critical two-tailed.

After extraction of simethicone from a dense matrix such as citric acid, peppermint oil, sodium methyl $p$-hydroxybenzoate, sodium propyl $p$-hydroxybenzoate, saccharin sodium, sorbitol $70 \%$ solution and mannitol with a simple method and quantification by an absolute method, a different product form was tried. This time, the gravimetric method was studied on the oral drop form, where only simethicone was used as a drug active ingredient in a dense placebo content. The results of the accuracy and precision parameters performed met the ICH criteria.

This proposed gravimetric method is relatively easy and economical to the analytical methods mentioned earlier. Besides being reliable and very fast, it is suitable for quality control analysis. Since it is an absolute method, it does not require linearity, and therefore a calibration chart. With all these proofs and reasons, it is stated that this validated gravimetric analysis can be used in pharmaceutical products containing simethicone.

\section{Acknowledgements}

This work was supported by the World Medicine Pharmaceutical Industry and Trade Inc. The authors are thankful to the company, for providing necessary instrumental facilities and chemicals to carry out the research work.

\section{Supporting Information}

Supporting information accompanies this paper on http://www.acgpubs.org/journal/journal-ofchemical-metrology

\section{ORCID}

Müge Güleli: 0000-0002-1539-3228

Sezin İşsever: $0000-0003-2469-947 \mathrm{X}$

Cem Çalışkan: 0000-0003-2345-0242

Mahmut Özbek: 0000-0002-6505-3811

\section{References}

[1] A. Rohman, A. Musfiroh and E. G. Wijaya (2013). Quantitative determination of simethicone in antacid suspension and chewable tablet using ftır spectroscopy, Glob. J. Pharmacol. 7 (3), 270-275.

[2] J.A. Rider (1968). Experience with the use of defoaming agent in the treatment of gastrointestinal gas, Ann. N. Y. Acad. Sci. 50, 170-177.

[3] A. D. Hargis and L. B. Whittall (2013). Improvements in soft gelatin capsule sample preparation for USP-based simethicone FTIR analysis, J. Pharmaceut. Biomed. Anal. 74, 223-226.

[4] K. Mojsiewicz- Pieńkowska (2012). Size exclusion chromatography with evaporative light scattering detection as a method for speciation analysis of polydimethylsiloxanes. III. Identification and determination of dimeticone and simeticone in pharmaceutical formulations, J. Pharmaceut. Biomed. Anal. 58, 200-207. 
[5] A. Suneetha, N. Sharmila and M. Purnima (2017). Stability indicating RP-HPLC method for the determination \& validation of loperamide hydrochloride \& simethicone in pharmaceutical dosage form, World J. Pharm. Pharmaceut. Sci. 6 (9), 955-971.

[6] D. E. Moore, T. X. Liu, W. G. Miao, A. Edwards and R. Elliss (2002). A RP-LC method with evaporative light scattering detection for the assay of simethicone in pharmaceutical formulations, J. Pharmaceut. Biomed. Anal. 30, 273-278.

[7] B. M. Latha, M. D. Noorjahan and A. Madhukar (2018). A new RP-HPLC method for the simultaneous estimation of magaldrate and simethicone in bulk and tablet dosage form as per ICH guidelines, J. Synth. Nat. Chem. 3 (1), 31-34.

[8] P. K. Pandey, M. Patel, P. Wadhwa and S. K. Sahu (2020). Simultaneous estimation for Dicyclomine HCl and Simethicone in bulk and oral liquid drop formulation: an RP-HPLC method development and validation, Futur. J. Pharmaceut. Sci. 6, article number 12, https://doi.org/10.1186/s43094-020-00029-x

[9] Simethicone, British Pharmacopeia, 2020.

[10] Simethicone, US Pharmacopeia, 2020.

[11] G. Torrado, A. García-Arieta, F. de los Ríos, J. C. Menéndez and S. Torrado (1999). Quantitative determination of dimethicone in commercial tablets and capsules by fourier transform infrared spectroscopy and antifoaming activity test, J. Pharmaceut. Biomed. Anal. 19, 285-292.

[12] H. Zeng, M. Gao, Ning Zhang, X. Wu, X. Luo, L. Luo and Y. Luo (2016). Determination of simethicone dry suspension by IR, Latin Am. J. Pharm. 35 (1), 5-10.

[13] L. Luo, F. Wang, X. Luo, H. Zeng and Y. Luo (2016). Determination of polydimethylsiloxane in a new simethicone emulsion formulation using IR, Latin Am. J. Pharm 35 (6), 1348-1353.

[14] I. Musfiroh, A. N. Hasanah, G. A. Faradiba, I. Ayumiati, M. Mutakin and M. Muchtaridi (2019). Modification of extraction methods on determining simeticone suspension using FTIR Method, Indones. J.Pharmaceut. Sci. Technol. $6(3), 125-133$.

[15] H. Han, H. Yılmaz and İ. Gülçin (2018). Antioxidant activity of flaxseed (Linum usitatissimum L) shell and analysis of its polyphenol contents by LC-MS/MS, Rec. Nat. Prod. 12, 397-402

[16] ICH Guideline, "Validation of analytical procedures: text and methodology," in Proceedings of International Conference on Harmonization, Topic Q2 (R1), Geneva, Switzerland, November 2005.

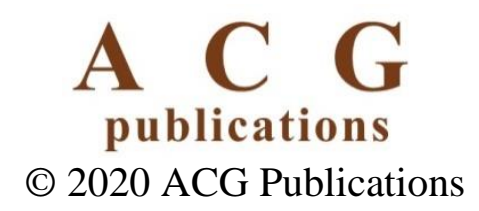

